\title{
A ATUAÇÃO DO PEDAGOGO NOS ESPAÇOS NÃO ESCOLARES NO MUNICÍPIO DE CAMPOS DOS GOYTACAZES, RJ
}

\section{Janine Lopes Heringer Morellato ${ }^{*^{*}}$, Mariana Peixoto Artiles Cavalhiére da Silva ${ }^{1}$, Teresa Claudina de Oliveira Cunha ${ }^{1}$ \& Vânia Machado Seabra Puglia ${ }^{1}$}

\section{RESUMO}

MOREllato, J. L. H.; SilVA, M. P. A. C.; CUNHA, T. C. O.; PUGliA, V. M. S. A atuação do pedagogo nos espaços não escolares no município de Campos dos Goytacazes, RJ. Perspectivas Online: Humanas \& Sociais Aplicadas, v.10, n.27, p.63 - 832020.

Essa pesquisa teve como objeto de investigação a atuação do pedagogo em espaços não escolares. A Pedagogia foi compreendida como uma ciência em que a atuação era somente em espaços escolares, onde o pedagogo atuava com o trabalho de gestão, de coordenação pedagógica e docência. A partir de 2006, com a publicação das Diretrizes Curriculares Nacionais para o Curso de Pedagogia, seus espaços de prática profissional são expandidos na sociedade, deixando de ser vista apenas com uma atuação em atividades de educação e ensino. A população pesquisada envolveu 06 pedagogos que atuam em espaços não escolares no município de Campos dos Goytacazes, RJ. O método utilizado para coleta de dados foi a entrevista padronizada. Foram analisados o perfil do profissional, os aspectos relacionados à motivação e à autoavaliação, bem como os desafios e as dificuldades enfrentados no cotidiano profissional. $\mathrm{O}$ estudo possibilitou a organização e a ampliação de conhecimentos da prática profissional do pedagogo em espaços não escolares. A pesquisa apresenta o contexto profissional das áreas da pedagogia hospitalar, social e empresarial, demonstrando que o enfoque educativo da pedagogia não está presente somente no contexto escolar, mas também no não escolar. A educação possui total relação com o trabalho que se desenvolve em suas respectivas instituições, tornandose, então, parte essencial para a sua atuação.

Palavras-chave: Pedagogia Não-Escolar; Educação; Atuação do Pedagogo. 


\begin{abstract}
The objective of this research was to investigate the performance of the pedagogy in non-academic settings. Pedagogy was understood as a science in which acting was only in school environments, where the pedagogue worked within the realm of management, pedagogical coordination and teaching. As of 2006, with the publication of the National Curricular Guidelines for the Pedagogy Courses, their places of professional practice are expanded in society, and are no longer seen only in educational practices. The researched population involved six pedagogues that work in no-school spaces in the municipality of Campos dos Goytacazes, RJ. The method used for data collection

was the standardized interview. The profile of the professional, the aspects related to motivation and self-assessment, as well as the challenges and difficulties faced in the professional daily life were analyzed. The study allowed the organization and expansion of knowledge of the professional practice of the pedagogue in non-academic places. The research presents the professional context of the areas of the hospital, social and business pedagogy, demonstrating that the educational approach of pedagogy is not present only in the school context, but also in the non-school context. Education is completely related to the work they do in their respective institutions and is therefore an essential part of their work
\end{abstract}

Keywords: Non-Academic Pedagogy; Education; Role of the Pedagogue

\footnotetext{
${ }^{1}$ Institutos Superiores de Ensino do CENSA - ISECENSA - Laboratório de Formação de Professor - LAFORP - Rua Salvador Correa, 139, Centro, Campos dos Goytacazes, RJ, CEP: 28035-310, Brasil.

(*) e-mail: janinelopesheringer@gmail.com

Data de recebimento: 20/07/2019. Aceito para publicação:13/02/2020.
}

Persp. Online: hum \& sociais aplicada., Campos dos Goytacazes, 27 (10) 63-82-2020 


\section{INTRODUÇÃ̃O}

\subsection{Pedagogia: um breve histórico}

No Brasil, durante um longo tempo, a Pedagogia foi compreendida como uma ciência em que a presença era somente em espaços escolares, onde o pedagogo atuava com o trabalho de gestão, de coordenação pedagógica e docência. A partir de 2006, com a publicação das Diretrizes Curriculares Nacionais para o Curso de Pedagogia, seus espaços de prática são expandidos na sociedade, deixando de ser vista apenas com uma atuação em atividades de educação e ensino. Agora, apresenta-se com uma diversidade de trabalhos pedagógicos, procurando atender às demandas da sociedade como um todo: empresas, espaços sociais, hospitais, entre outros (PIMENTA, 2011).

Giroux (1993 apud LIBÂNEO, 2001, p. 17) afirma que a Pedagogia, enquanto campo científico, foi perdendo espaço acadêmico a partir de 1920, com o movimento da educação nova, mais tarde, com o tecnicismo educacional, e, posteriormente, com a onda críticoreprodutivista dos anos 1970-1980.

José Carlos Libâneo (2001, p. 15) afirma que está

acentuada a consciência atual da importância e da necessidade da intervenção participante e eficaz desses profissionais no âmbito das práticas socioculturais desenvolvidas, tendo em vista que processos pedagógicos informais estão sempre implícitos nas práticas, efetivadas no plano coletivo e comunitário. [...]

Nos dias atuais, a sociedade se encontra com uma pluralidade cultural bem presente e há uma grande diversidade conceitual. Universalmente, o curso de Pedagogia está ligado com o saber e com a maneira que pode conduzi-lo, podendo ser em espaços escolares e não escolares.

Pedagogia é, antes de tudo, um campo científico, não um curso. O curso que lhe corresponde é o que forma o investigador da educação e o profissional que realiza tarefas educativas seja ele docente ou não diretamente docente. (...) cuja natureza constitutiva é a teoria e a prática da educação ou a teoria e prática da formação humana (PIMENTTA, 2011, p. 64).

Libâneo (2001, p. 12) destaca ainda que:

O curso de Pedagogia se destina a formar o pedagogo-especialista, isto é, um profissional qualificado para atuar em vários campos educativos, para atender demandas socioeducativas (de tipo formal, não-formal e informal) decorrentes de novas realidades, tais como novas tecnologias, novos atores sociais, ampliação do lazer, mudanças nos ritmos de vida, sofisticação dos meios de comunicação. Além disso, informar as mudanças profissionais, desenvolvimento sustentado, preservação ambiental, nos serviços de lazer e animação cultural, nos movimentos sociais, nos serviços para a terceira idade, nas empresas, nas várias instâncias de educação de adultos, nos serviços de psicopedagogia, nos programas sociais, na televisão e na produção de vídeos e filmes, nas editoras, na educação especial, na requalificação profissional etc.

A educação é um subsistema pertencente ao sistema educacional que ocorre em múltiplos espaços, a partir da interação com o outro. Almeida (2010, p. 130) afirma que o

Persp. Online: hum \& sociais aplicada., Campos dos Goytacazes, 27 (10) 63-83-2020 
pedagogo é o profissional competente para desenvolver uma práxis comprometida com a transformação social, que não colabore para perpetuar o distanciamento entre o saber da experiência e o saber sistematizado, mas que valorize esses saberes que são distintos, porém complementares.

Sobre essa questão, Franco (2008 apud SEVERO, 2017, p. 131) destaca que

Como qualquer campo científico, a Pedagogia é confrontada por demandas que atravessam o universo das práticas educativas associadas ao desenrolar da história em seus múltiplos nexos, de modo que faz sentido afirmar a necessidade de que '[...] que se reivindique à Pedagogia um estudo contemporâneo que possa absorver as especificidades do momento histórico atual'.

A pedagogia é, portanto, uma ciência que tem como objeto de estudo a educação, com base no desenvolvimento humano e não apenas a formação escolar, estando inserida no contexto social. Pimenta (2010 apud SEVERO, 2017, p. 133) diz que "a educação como objeto da Pedagogia revela-se como: [...] inconcluso, histórico, que constitui o sujeito que o investiga e é por ele constituído".

O pedagogo, dessa forma, exerce a sua função em vários lugares em que se tem a prática educativa, seja ela direta ou não, formal ou informal, ligada à sistematização nos processos de transferência e absorção dos saberes e maneiras de agir, tendo como objetivo principal a formação humana na sociedade em que atua. diz:

Holanda (2011, p. 3) apresenta ainda a pedagogia de forma mais generalista, quando

O conceito de pedagogia mais generalizado é o que faz referências à ciência da educação social das pessoas e grupos, por um lado, e por outro, a partir de uma vertente educativa, o individual socializa - se dentro e fora da instituição escolar e, por isso, a educação social deve efetivar em todos os contextos nos quais se desenvolve a vida do ser humano.

Dentro desse contexto, um dos maiores desafios da atualidade acadêmica em relação ao curso de pedagogia tem sido preparar profissionais que estejam aptos a intervir de forma significativa na formação do indivíduo, seja ela formal ou não formal, com foco em sua totalidade, ou seja, agindo sobre o seu desenvolvimento intelectual, físico, moral e social.

O principal objetivo do pedagogo é a sua ação com fins educativos nos diferentes espaços de atuação, formando indivíduos críticos a fim da sua atuação na sociedade, tendo capacidade de criar e construir práticas que possibilitem atender às exigências de uma sociedade que está sempre em transformação.

Com o estabelecimento das DCN's para o Curso de Graduação de Pedagogia, em 2006, amplia-se o leque do perfil do profissional (perfil, atribuições, funções, mercado) que, anteriormente, tinha um foco principal na formação de profissionais para atuar em espaços escolares, o que restringia seu campo de atuação.

A Pedagogia, atualmente, é considerada um campo bem reconhecido nas diversas universidades quanto à formação de professores e pedagogos, levando-se em conta as necessidades do mundo globalizado. As Diretrizes Curriculares Nacionais da Graduação do Curso de Pedagogia ressaltam a relevância da atuação do profissional nas diferentes fases do desenvolvimento humano, quando no inciso IV do artigo $5^{\circ}$ estabelece "trabalhar, em espaços

Persp. Online: hum \& sociais aplicada., Campos dos Goytacazes, 27 (10) 63-83-2020 
escolares e não escolares, na promoção da aprendizagem de sujeitos em diferentes fases do desenvolvimento humano, em diversos níveis e modalidades do processo educativo".

$\mathrm{O}$ artigo $5^{\circ}$ das DCN's destaca também algumas funções cabíveis ao pedagogo:

XIII - participar da gestão das instituições planejando, executando, acompanhando e
avaliando projetos e programas educacionais, em ambientes escolares e não-
escolares; XIV - realizar pesquisas que proporcionem conhecimentos, entre outros:
sobre alunos e alunas e a realidade sociocultural em que estes desenvolvem suas
experiências não escolares; sobre processos de ensinar e de aprender, em diferentes
meios ambientais ecológicos; sobre propostas curriculares; e sobre organização do
trabalho educativo e práticas pedagógicas (...) (BRASIL, 2006).

A formação do pedagogo, portanto, apresenta cada vez mais demandas. As DCN's apontam os diversos espaços de atuação profissional:

Art. $5^{\circ} \mathrm{O}$ egresso do curso de Pedagogia deverá estar apto a:

I - atuar com ética e compromisso com vistas à construção de uma sociedade justa, equânime, igualitária;

II - compreender, cuidar e educar crianças de zero a cinco anos, de forma a contribuir, para o seu desenvolvimento nas dimensões, entre outras, física, psicológica, intelectual, social;

III - fortalecer o desenvolvimento e as aprendizagens de crianças do Ensino Fundamental, assim como daqueles que não tiveram oportunidade de escolarização na idade própria;

IV - trabalhar, em espaços escolares e não-escolares, na promoção da aprendizagem de sujeitos em diferentes fases do desenvolvimento humano, em diversos níveis e modalidades do processo educativo (BRASIL, 2006).

Os DCN's também preveem a atuação do pedagogo em processos de gestão escolar e não escolar, demonstrando, assim, a diversidade de trabalhos pedagógicos para além das atividades de educação escolar e ensino, garantindo a igualdade de direitos em diversas dimensões:

É central a participação na gestão de processos educativos, na organização e funcionamento de sistemas e de instituições de ensino, com a perspectiva de uma organização democrática, em que a corresponsabilidade e a colaboração são os constituintes maiores das relações de trabalho e do poder coletivo e institucional, com vistas a garantir iguais direitos, reconhecimento e valorização das diferentes dimensões que compõem a diversidade da sociedade, assegurando comunicação, discussão, crítica, propostas dos diferentes segmentos das instituições educacionais escolares e não - escolares (BRASIL, 2005).

As Diretrizes Curriculares Nacionais para o curso de Pedagogia apresentam os diversos campos de atuação que o profissional da Pedagogia pode atuar, compreendendo que este campo não é restrito, e que é uma valiosa experiência que ultrapassa valores, princípios e os contextos sociais e políticos. Com isso, constrói um novo perfil do profissional de pedagogia, assegurando suas diversas formas de atuar nos espaços.

\subsection{Pedagogia não-escolar}

É importante ressaltar que a partir do momento que ocorre uma mudança de conceitos por parte de toda uma sociedade e, principalmente, da classe de trabalhadores causada pela era tecnológica, emerge a necessidade de um profissional que lide com todas essas transformações e que, por meio de suas didáticas, atue em prol das organizações, sempre visando ao seu benefício.

Persp. Online: hum \& sociais aplicada., Campos dos Goytacazes, 27 (10) 63-83-2020 
Sobre a educação não escolar, Severo (2017, p. 130) afirma que:

A inserção da Educação Não Escolar no âmbito pedagógico constitui-se como uma
demanda histórica, pois responde às necessidades emergentes da complexidade que
se revela no modo de estruturação e de comportamento das sociedades globalizadas.
Por isso, é importante demonstrar o caráter pedagógico da Educação não escolar e
ressalta a sua importância para a promoção de processos que potencializem a
educabilidade humana em tempos nos quais as pessoas são confrontadas por
múltiplas possibilidades e demandas de ensinar e aprender, de educar e de se educar.

Necessária se faz a construção ou a reflexão sobre a importância da atuação do pedagogo em espaços não escolares, a partir de sua definição.

Nessa etapa do estudo, pretende-se ater aos espaços não escolares, demonstrar que práticas educativas podem ser ministradas ultrapassando os muros escolares e transcorrendo por demais âmbitos sociais. Neste aspecto, Felden (2013 apud LIBÂNEO, 2001, p. 14) enfatiza:

Proponho que os profissionais da educação formados pelo curso de Pedagogia venham a atuar em vários campos sociais da educação, decorrentes de novas necessidades e demandas sociais a serem regulados profissionalmente. Tais campos são: as escolas e os sistemas escolares; os movimentos sociais; as diversas mídias, incluindo o campo editorial; as áreas da saúde; as empresas; os sindicatos e outros que se fizeram necessários.

Ressalta-se que, no trabalho em espaços não escolares, utilizam-se métodos e recursos diferentes do trabalho feito no espaço escolar. Sobre essa questão, Melo (2012, p. 5) relata que:

\begin{abstract}
A mobilização dos saberes acontece para atender as necessidades do trabalho pedagógico, e está relacionada ao domínio dos conhecimentos adquiridos pelo Pedagogo já ressignificados pelo e no trabalho pedagógico no momento da sua realização efetiva. A articulação da diversidade de conhecimentos adquiridos ao longo de formação e da prática profissional atribui um novo e / ou real sentido. Já a sua utilização está ligada à seleção dos saberes mobilizados para atender as necessidades do trabalho pedagógico. Libâneo, chama a atenção para uma distinção entre 'trabalho pedagógico (atuação profissional em um amplo leque de práticas educativas) e trabalho docente (forma peculiar que o trabalho pedagógico assume na sala de aula)'.
\end{abstract}

No entanto, é de suma importância ressalvar que essas atuações se dialogam, uma vez que ambas possuem objetivos semelhantes, como o desenvolvimento humano e as suas múltiplas capacidades.

Severo (2015, p. 150) acrescenta da seguinte forma:

É legítimo pensar que o que se espera de um pedagogo em Espaços Não Escolares muitas vezes dialoga com as habilidades necessárias ao trabalho do pedagogo na escola como professor. A prática do magistério, da gestão e da pesquisa em Pedagogia segue orientações teleológicas que se associam a concepções de sujeito e sociedade que transcendem o cenário em que as práticas educativas ocorrem, pois são intrínsecas ao próprio sentido emancipador da educação. Desse modo, grande parte dos saberes e habilidades declaradas nas DCN's que são, em vários casos, reproduzidas nos PPC's, pode ser sobreposta tanto no campo do Espaço Não Escolar quanto no campo da Educação Escolar.

Persp. Online: hum \& sociais aplicada., Campos dos Goytacazes, 27 (10) 63-83-2020 
Percebe-se, dessa forma, a complexidade existente entre trabalho do pedagogo não escolar e o escolar. Portanto, é urgente que esse profissional tenha o pleno conhecimento desses papéis para que busque, com excelência, a execução de sua função em qualquer espaço em que venha atuar.

Sobre a educação não escolar, Severo (2017, p. 133-134) afirma que a:

Educação Não Escolar (ENE) consiste em um termo cuja conceituação resulta de uma necessidade histórica emergente, dado o atual contexto de fortalecimento do caráter estruturado de práticas educativas para além dos limites da escola. Se, na maior parte do tempo, a Pedagogia e a sociedade, em geral, deixaram de focalizar a ENE como problema pedagógico, a atualidade tem sido cenário de proliferação de iniciativas cada vez mais visíveis de desenvolvimento de processos formativos em espaços não convencionais de ensino e aprendizagem.

A sociedade atual vive em constante evolução, apresentando os avanços tecnológicos em diversos campos, implantando uma nova visão de trabalho como a indústria 4.0, o que implica mudanças no mercado de trabalho. Com isso, há novos sistemas de organização de trabalho, mudanças no perfil profissional e uma exigência de uma melhor qualificação de trabalhadores que acabam atingindo sistemas de ensino. Por isso, faz-se necessário ter um profissional de pedagogia capaz de lidar com todas essas demandas nos espaços não formais.

\subsubsection{Das áreas de atuação não escolar}

Selma Garrido Pimenta (2011, p. 76-77) destaca que:

O curso de Pedagogia destina-se à formação de pedagogos-especialistas que venham a atuar em vários campos sociais da educação, decorrentes de novas necessidades e demandas socioculturais e econômicas. Tais campos são: as escolas e os sistemas escolares, a pesquisa educacional, os movimentos sociais, as diversas mídias, incluindo o campo editorial, as áreas da saúde e assistência social, as empresas, os sindicatos, as atividades de animação cultural e lazer e outros que se fizerem necessário.

Em todos esses campos de atuação, o pedagogo poderá, portanto, desenvolver atividades de planejamento, organização, coordenação, gestão de sistemas de ensino, assistência, formação de profissionais educacionais e formulação e execução de projetos. Especificamente, a Pedagogia se refere a um diálogo entre teoria e prática que independe do campo de atuação. Um conjunto de conhecimentos que estão sempre interligados e esse diálogo precisa fazer parte da formação do profissional.

Sobre o exercício profissional do pedagogo, Felden (2013, p. 71) destaca:

Justifica-se esse olhar para a Pedagogia, pois o exercício profissional do pedagogo tem sido ampliado significativamente nas últimas décadas. Para tanto, é urgente construir uma sólida fundamentação teórica, com precisas concepções conceituais, considerando os vários âmbitos que compõem a atuação científica e profissional desse campo educacional. A preocupação é com o avanço do processo de formação desses profissionais da educação e, consequentemente, a garantia de qualidade dessa formação, possibilitando que as práticas educativas realizadas por educadores, correspondam aos anseios e expectativas da sociedade.

Nessa direção, com base no fato de que a pedagogia se refere ao diálogo entre teoria e prática educativa realizada por professores e pedagogos em diferentes espaços, Libâneo (2001, p. 161) diz:

Persp. Online: hum \& sociais aplicada., Campos dos Goytacazes, 27 (10) 63-83-2020 
Quem, então, pode ser chamado de pedagogo? O pedagogo é o profissional que atua em várias instâncias da prática educativa, direta ou indiretamente ligadas à organização e aos processos de transmissão e assimilação de saberes e modos de ação, tendo em vista o objetivo de formação humana previamente definidos em sua contextualização histórica.

A pedagogia é, portanto, realizada como práticas efetivas, desenvolvidas por educadores que têm um importante papel no sentido de renovar e ressignificar, diante dos educandos e juntamente com eles, a sua própria maneira de aprender e conhecer. Essa atividade é necessária para que haja uma responsabilidade em garantir uma formação capaz de articular os conhecimentos teóricos com a prática educativa.

Segundo Libâneo, Oliveira e Toschi (2011, p. 168), é necessário destacar que "a prática educativa envolve a presença de sujeitos que ensinam e aprendem ao mesmo tempo, de conteúdos (objetos de conhecimentos a serem apreendidos), de objetivos, de métodos, de técnicas coerentes com os objetivos desejados".

Nos espaços não escolares, o pedagogo também tem seu papel significativo em sua atuação, marcado por práticas educativas. Felden (2013, p. 76-77) afirma que "o pedagogo poderá implantar e coordenar projetos no campo de desenvolvimento de recursos humanos, particularmente em trabalho de formação de pessoas, sendo inclusive responsável pela qualificação dos indivíduos".

O papel do pedagogo é o de possibilitar mudanças de qualidade no desenvolvimento e na aprendizagem dos indivíduos, visando auxiliá-las a serem sujeitos participativos e a ajudar a melhorar a sua capacidade de ação e as suas aptidões para viver e agir na sociedade em que se vive.

\subsubsection{Da Pedagogia Hospitalar}

Visto que a finalidade do pedagogo é a educação, que tem como essência do seu trabalho o processo de ensino-aprendizagem, e que está presente em diversos espaços, vê-se uma oportunidade de atuação do pedagogo em hospitais, que se faz pela Pedagogia Hospitalar, local em que o pedagogo utiliza de suas práticas pedagógicas no auxílio ao hospitalizado.

\footnotetext{
A legislação brasileira reconhece o direito de crianças e jovens hospitalizados ao atendimento pedagógico-educacional. A Declaração dos Direitos da Criança e do Adolescente Hospitalizados decorreu de formulação da Sociedade Brasileira de Pediatria e da Resolução do Conselho Nacional dos Direitos da Criança e do Adolescente, com a chancela do Ministério da Justiça em 1995 (FONSECA, 1999, p. 119).
}

O pedagogo exerce um papel significativo no hospital, pois possibilita que a criança e/ou adolescente tenham participação ativa na sociedade, dando continuidade aos seus estudos, não deixando que se sintam excluídos e menosprezados. A educação diz respeito às pessoas durante toda a vida, e isso se aplica para uma pessoa enferma. A Pedagogia Hospitalar propõe uma ajuda pedagógica eficaz, possibilitando aos indivíduos, mesmo que em ambientes diferentes, que continuem suas atividades e se sintam fazendo parte da sociedade, dando assim continuidade em sua vida.

Segundo Silva e Andrade (2013, p. 104),

Persp. Online: hum \& sociais aplicada., Campos dos Goytacazes, 27 (10) 63-83-2020 seer.perspectivasonline.com.br 
as Diretrizes Curriculares apontam que a formação contribuirá na atuação do pedagogo em ambientes hospitalares quando diz: fortalecer o desenvolvimento e as aprendizagens de crianças; trabalhar, em espaços escolares e não escolares; reconhecer e respeitar as manifestações e necessidades físicas, cognitivas, emocionais, afetivas dos educandos nas suas relações individuais e coletivas.

Matos e Mugiatti (2006, p. 47), em seu livro de "Pedagogia Hospitalar", afirmam que:

A educação que se processa, por meio da Pedagogia Hospitalar, não pode ser identificada como simples instrução (transmissão de alguns conhecimentos formalizados). É muito mais que isto. É um suporte psico-sociopedagógico dos mais importantes, porque não isola o escolar na condição pura de doente, mas, sim, o mantém integrado em suas atividades da escola e da família e apoiado pedagogicamente na sua condição de doente.

A educação se expressa como direito de escolarização e aprendizagem em diversos contextos e espaços na sociedade. Cabe também ao Poder Público ofertar o acesso aos diversos níveis de educação, podendo ser feito de diversas formas para obter a aprendizagem.

A Lei de Diretrizes e Bases da Educação Nacional (1996), em seu art. 5º, estabelece, como dever do Estado, a garantia da educação básica obrigatória, o cumprimento da obrigatoriedade de ensino, cabendo, portanto, ao Poder Público criar formas alternativas de acesso aos diferentes níveis de ensino, podendo, segundo o artigo 23 da LDB, organizar-se "por forma diversa de organização, sempre que o interesse do processo de aprendizagem assim o recomendar".

O Ministério da Educação (BRASIL, 2002, p. 12) compreende que pessoas hospitalizadas, isto é, impossibilidade de frequência à escola, "necessitam de formas alternativas de organização e oferta de ensino de modo a cumprir com os direitos à educação e à saúde, tal como definidos na Lei e demandados pelo direito à vida em sociedade".

Sobre o papel do pedagogo, Elizete Lúcia Moreira Matos e Margarida Maria Teixeira de Freitas Muggiatti (2006, p. 37) afirma que:

\begin{abstract}
Além de garantir o direito escolar do enfermo à escolarização, acredita-se que o pedagogo possa estar atuando integradamente em diversos setores do hospital. O pedagogo hospitalar pode promover ações educativas junto às diversas possibilidades no hospital, dentre elas, pessoas idosas, com vistas ao bem-estar completo, isto é, físico, mental, social, educacional, dentre outras possibilidades que aí se apresentam; a educação numa dimensão integrada aos diversos setores da área de saúde, promovendo cuidados com a própria saúde, as práticas de sociabilidade, resgate da autoestima e autoavaliação.
\end{abstract}

Junto com a equipe multidisciplinar, o pedagogo, com estratégias apropriadas, atua, no hospital, analisando qual atividade lúdica para o tipo de faixa etária, além de planejar e executar projetos, visa não só ao intelectual do paciente, mas também ao seu social e psicológico, porém ele não deve ser o único responsável pela aprendizagem, os pacientes devem ter participação ativa no seu processo de ensino-aprendizagem, expondo aquilo que considera pertinente. Como afirma Paulo Freire (2015, p. 24) "quem ensina aprende ao ensinar e quem aprende ensina ao aprender".

\title{
1.2.1.2. Pedagogia Empresarial
}

Para Chiavenato (2000, p. 4), a sociedade contemporânea está a exigir o crescimento das e nas organizações, o que demanda cada vez mais "uma maior complexidade dos recursos

Persp. Online: hum \& sociais aplicada., Campos dos Goytacazes, 27 (10) 63-83-2020 
necessários às suas operações, com o aumento de capital, incremento de tecnologia, atividades de apoio etc. (...)", bem como a necessidade de profissionais qualificados, com uma postura voltada ao autodesenvolvimento e à aprendizagem contínua e que, consequentemente, sejam capazes de "intensificar a aplicação de seus conhecimentos e habilidades".

Num mundo globalizado, com a introdução das novas tecnologias na esfera do trabalho, houve transformações muito intensas na sociedade e, como não poderia deixar de ser, também no âmbito empresarial, que, em busca da lucratividade, demanda por profissionais cada vez mais qualificados, atentos às necessidades da empresa, colaborativos, que saibam se relacionar entre si, dentre outras características. Assim como no campo hospitalar, outro espaço de atuação do profissional da Pedagogia é o empresarial. O profissional da Pedagogia, nessa conjuntura, auxilia no propósito de sanar todas essas necessidades, em prol de um desenvolvimento posterior. No entanto, segundo Trevisan e Lameira (2003 apud TORRES; CLARO, 2012, p. 208) "o mercado desconhece a importância deste profissional no contexto empresarial".

Sobre esse contexto, Lopes, Trindade e Cadinha (2008, p. 32) afirmam que:

A Pedagogia Empresarial, se apresenta como uma ponte entre o desenvolvimento das pessoas e as estratégias organizacionais. Isto porque, como já foi abordado, a Pedagogia é a ciência que estuda de forma sistematizada o ato educativo, isto é, a prática educativa concreta que se realiza na sociedade.

O pedagogo desempenha um papel fundamental nas empresas, que é o de trabalhar com a educação e priorizar a formação dos indivíduos que convivem ali. Ribeiro (2008, p. 38) ressalta que o pedagogo "saberá discernir melhor as necessidades de treinamento/formação, planejando cada atividade com clareza, identificando o que, de fato, constitui-se como prioridade".

Para Torres e Claro (2012, p. 209),

\begin{abstract}
A capacidade da empresa de adaptar-se às exigências do mercado depende da forma como esta estimula seus colaboradores a buscar, refletir e aplicar conhecimentos. Paralelamente, amplia-se a percepção de que as empresas dependem de seu Capital Humano para inovar, e os aspectos intangíveis relacionados à Gestão de Pessoas ganham cada vez mais destaque.
\end{abstract}

O pedagogo, portanto, com toda a sua formação e qualificação didática, pode atuar dentro da empresa com elaboração de projetos e treinamentos que visem ao desenvolvimento humano. Com isso, nota-se a intensa relação das capacidades utilizadas em espaços escolares, presente no espaço não escolar. Esse profissional tem a capacidade de encontrar as reais necessidades a serem trabalhadas no ambiente em que está inserido e qual deverá ser a prioridade a ser abordada. Para Quirino (2005, p. 71),

O Pedagogo tem em sua formação acadêmica toda uma bagagem necessária para transformar a prática educativa, onde quer que ela aconteça, em uma atividade intencional e eficaz, orientando-a, não só para alcançar os objetivos organizacionais, mas, sobretudo para as finalidades sociais e políticas da educação criando um conjunto de condições metodológicas e organizativas para viabilizá-la.

Um dos espaços de atuação do Pedagogo dentro da empresa é na área de gestão de pessoas, colaborando constantemente para o desenvolvimento pessoal dos profissionais a fim de desenvolver cada vez mais as suas habilidades e capacidades, trazendo consequentes benefícios para a empresa e mercado em que a mesma está inserida.

Persp. Online: hum \& sociais aplicada., Campos dos Goytacazes, 27 (10) 63-83-2020 
Trevisan e Lameira (2012) ressaltam, no entanto, que o pedagogo nas organizações, mesmo que possa ser um parceiro, não vai desenvolver atividades voltadas ao incremento da produtividade ou do lucro, mas vai atuar com o foco na aprendizagem permanente, no aperfeiçoamento e no desenvolvimento profissional.

\title{
1.2.1.3. Pedagogia Social
}

Para a melhor compreensão desse campo de atuação profissional do pedagogo, buscarse-á, inicialmente, definir Pedagogia Social, que ocupa um espaço fundamental no núcleo das ciências da educação. Segundo Carvalho et al. (2009, p. 96),

\begin{abstract}
A Pedagogia Social é uma aplicação das ideias de Rudolf Steiner sobre organização social, formuladas em 1919 com o nome de 'Trimembração do Organismo Social' que significa 'agir sobre si mesmo, com os outros e com as perguntas da sociedade, de tal forma que nossa ação torne possível o desenvolvimento sadio de outras pessoas e das condições sociais'. Com isso o pedagogo social surgiu para tentar resolver ou minimizar os problemas apresentados no contexto coletivo.
\end{abstract}

Para Passos (2017, p. 3),

o Campo da Pedagogia que se constrói, dialoga, transita e agrega sistematicamente os conhecimentos e saberes construídos do Serviço Social, Sociologia, Filosofia, Psicologia Social, Educação Social, Educação Comunitária, da Educação Popular defendida por Paulo Freire em seus diversos trabalhos, bem como os saberes de experiência produzidos pela humanidade.

O trabalho do pedagogo social ocorrerá em asilos, abrigos, dentre outros espaços, fazendo de suas práticas, métodos de caráter educativos. Através de sua atuação, emerge uma grande influência para modificar positivamente o meio em que está inserido, buscando o desenvolvimento dos indivíduos envolvidos, de acordo com suas dificuldades e necessidades e para isso se faz necessário que esse profissional atue como um gestor e trabalhe também na execução de projetos. Com isso, irá atuar detectando os problemas enfrentados pela sociedade ou grupo social em questão, buscando auxiliar na busca de melhorias.

Para Soares (2019, p. 2),

Pedagogia Social ou Educação Social envolve outras instâncias da sociedade como a família, instituições religiosas, espaços comunitários e, cada vez mais, há a requisição do trabalho do educador social ou pedagogo social na socio educação seja na política de assistência social ou medidas protetivas -, do judiciário e em empresariais, só para citar algumas.

Passos (2018, p. 4) afirma, ainda, que a pedagogia social ocorre em contextos sociais diferenciados e está estreitamente vinculada à realidade
de exclusão, desigualdades, marginalização, conflito social e abandono, uma vez
que, procura oferecer respostas positivas a milhares de pessoas vítimas de processos
de injustiça social, especialmente de violações de direitos. De uma forma ou de
outra, ela rejeita algumas práticas da escola que buscam explicar a conduta dessa
população pela ótica de um déficit de socialização primária e mesmo secundária,
como se o processo de socialização ocorresse num único momento da vida e não ao
longo da existência humana.

Independentemente dos motivos, todo indivíduo (seja criança, jovem ou adulto) que evade da escola tem a possibilidade de ser amparado por um profissional pedagogo, para que, por meio do conhecimento e pela busca do saber, possa se tornar um cidadão mais confiante,

Persp. Online: hum \& sociais aplicada., Campos dos Goytacazes, 27 (10) 63-83-2020 
presente na sociedade e participante não somente de seus deveres, mas também de seus direitos. Isso faz com que a realidade em que estão inseridos faça mais sentido e que tenha o real conhecimento do que perpassa nele, permitindo com que o pedagogo atue não apenas de forma a despertar o conhecimento, assim como o despertar da realidade vivida.

Pode-se perceber, portanto, que um dos principais focos do pedagogo, ao se tratar de pedagogia social, é a modificação, pois causa impactos transformadores na sociedade.

Diante do exposto, este estudo tem como objetivo principal compreender o papel do pedagogo nos espaços não escolares do município de Campos dos Goytacazes, RJ., bem como identificar os limites e as possibilidades que o pedagogo enfrenta na sua atuação em espaços não escolares.

\title{
2. METODOLOGIA
}

A população da pesquisa foi pedagogos que atuam em espaços não escolares, o que demandaria um tempo e logística muito grande. Ao invés disso, trabalhou-se com uma amostra de profissionais que fazem parte deste universo, as respostas desses profissionais irão representar o total de pedagogos. Ressalta-se também a ausência de um cadastro ou registro para um alcance maior de entrevistados. A pesquisa, portanto, envolveu 06 (seis) pedagogas que atuam em espaços não escolares no município de Campos dos Goytacazes, RJ.

Quanto à abordagem do problema, teve um enfoque qualitativo, de natureza exploratório-descritivo, com o objetivo de analisar todos os fatos presentes a serem investigados na pesquisa. Michel $(2009$, p. 36) afirma que:

\begin{abstract}
A pesquisa qualitativa considera que há uma relação dinâmica, particular, contextual e temporal entre o pesquisador e o objeto de estudo. Por isso, carece de uma interpretação dos fenômenos à luz do contexto, do tempo, dos fatos. O ambiente da vida real é a fonte direta para obtenção dos dados, e a capacidade do pesquisador de interpretar essa realidade, com isenção e lógica, baseando-se em teorias existente, é fundamental para dar significado às respostas.
\end{abstract}

Por meio de uma pesquisa de campo, pôde-se observar como é a atuação de cada pedagogo e todas as características que perpassam seu dia a dia. A pesquisa de campo foi realizada em diversas instituições, permitindo a análise da realidade do grupo pesquisado e seu impacto na transformação da sociedade. Ainda buscando Michel (2009, p. 42):

A pesquisa de campo, no ambiente natural, é particularmente importante na
pesquisa social, apropriada para estudo de indivíduos, grupos, comunidades,
organizações, sociedades, considerando que, para a pesquisa social, mais
importante que encontrar soluções é explicar os fenômenos, entender
realidades, criar significados sociais.

A pesquisa foi de caráter exploratório-descritivo, uma vez que foram levantadas informações sobre os objetos de estudo. Com isso, descreveram-se as características como forma de ampliar a compreensão acerca do comportamento desses profissionais em cada área, bem como seus métodos de ação.

As pesquisas exploratórias visam proporcionar maior familiaridade com o problema, com vistas a torná-lo mais explícito ou a construir hipóteses. Pode-se dizer que estas pesquisas têm como objetivo principal o aprimoramento de ideias ou a descoberta de intuições (GIL,1993 apud MICHEL, 2009, p. 40).

Persp. Online: hum \& sociais aplicada., Campos dos Goytacazes, 27 (10) 63-83-2020 
Ainda, com o objetivo de obtenção de informações, o instrumento de pesquisa foi o da entrevista (roteiro padronizado).

\section{RESULTADOS E DISCUSSÃO DOS DADOS}

Por se tratar de uma área de atuação não escolar, o estudo buscou-se compreender o papel do pedagogo nos espaços de atuação profissional. O Quadro 1 descreve a área de atuação e função/atividades desenvolvidas pelas profissionais.

Quadro 1: Distribuição das pedagogas, por área de atuação e função desenvolvida pelos sujeitos da pesquisa. Fonte: Pesquisa própria.

\begin{tabular}{|l|l|}
\hline \multicolumn{1}{|c|}{ ÁREA DE ATUAÇÃO } & \multicolumn{1}{|c|}{ FUNÇÃO } \\
\hline Pedagogia Social & $\begin{array}{l}\text { Elaboração e desenvolvimento de atividades que promovam } \\
\text { uma vida mais saudável para os idosos. }\end{array}$ \\
\hline Pedagogia Empresarial & Recrutamento e Seleção \\
\hline Pedagogia Hospitalar (2) & $\begin{array}{l}\text { Atuação com o foco no desenvolvimento de crianças } \\
\text { especiais juntamente com uma equipe multidisciplinar. }\end{array}$ \\
\hline Pedagogia Social & Atuação com projetos de medidas socioeducativas \\
\hline Pedagogia Social & $\begin{array}{l}\text { Coordenação das atividades pedagógicas (reforço escolar) } \\
\text { desenvolvidas junto às crianças e adolescentes, bem como } \\
\text { atividades junto à família (orientações de saúde, saneamento } \\
\text { básico, qualificação profissional) }\end{array}$ \\
\hline
\end{tabular}

A pesquisa buscou compreender esse universo de atuação que envolve um processo de trabalho didático-pedagógico de natureza abrangente. Para tanto, considerando a função/atividades desenvolvidas no espaço não escolar, perguntou-se qual a relação entre a educação e o trabalho desenvolvido.

"Envolve a questão cognitiva, na medida em que busca ensinar os conceitos básicos, e através dos brinquedos e brincadeiras, estimular a fala, a socialização, a integração, auxiliando no desenvolvimento da criança" (Depoimento da Pedagoga F. L.).

"Na instituição asilar, o pedagogo cumpre a importante função de socializar os conhecimentos disponíveis, promover o desenvolvimento cognitivo e a construção de normas de conduta inserida num mais amplo projeto social, procurando assim, controlar a necessidade de repressão. No entanto, a maioria das questões poderão ser tratadas de forma preventiva antes que se tornem verdadeiros "problemas", e também interventiva, se a dificuldade de aprendizagem já estiver evidente. $\mathrm{O}$ pedagogo tem uma amplitude em seu papel, como um profissional que através das atividades desenvolvidas e realizadas por uma equipe multidisciplinar, vem na tentativa de contribuir de forma positiva para os idosos, de maneira que, as atividades lúdicas, reflexivas e criativas possam encontrar alternativas de reinvenção de modo de vida e desvinculação de uma identidade correlata a inatividade, a decadência, ao isolamento, com resultados significativos para a sua qualidade de vida. Enfim, este projeto objetiva oferecer aos mesmos um espaço onde eles possam expressar suas angústias, seus desejos, suas opiniões, deixando aflorar suas virtudes, sua capacidade de agir, sentir, participar, refletir e criar" (Depoimento da Pedagoga E. J.). 
"É um trabalho que permite às crianças terem melhores condições de vida. Isso tem tudo a ver com educação, trabalha a memória, cognição, em especial, porque trabalhamos com crianças especiais, ajudando não só nas atividades escolares, como na vida. Temos projeto de trabalho educativo com os pais, como por exemplo, oficinas, palestras sobre educação e saúde, seminários sobre o autismo possibilitando que os mesmos entendam melhor o transtorno procurando $o$ tratamento adequado e entendendo a importância dele. Todo trabalho realizado lá, tem uma ponte com a família" (Depoimento da Pedagoga O. M.).

"Costumo falar que o trabalho que desenvolvo é como se fosse uma escola. O funcionário é como se fosse o aluno. Educar os funcionários a terem uma rotina, além da parte do incentivo à continuidade da formação. É uma educação diária. Sou corresponsável por projetos de capacitação de funcionários, como por exemplo, a preparação de seminários" (Depoimento da Pedagoga R. T.).

"A relação entre o educar e o social. Aqui, quando começo a trabalhar as questões pedagógicas, "bato de frente" com as questões sociais. É a Pedagogia Social, um trabalho não só visando a questão escolar, mas também a inclusão da comunidade, com projetos, a formação cultural da comunidade, são ações voltadas para questões educativas. Desde do princípio da minha perspectiva pedagógica social ela é baseada em tentativas de encontrar soluções reacionais para os problemas sociais que aqui existe, uma coisa está ligada a outra. Estou inserida nesse projeto com objetivo não só de desenvolvimento cognitivo a essas crianças e adolescentes, mas também a relação sócio emocional" (Depoimento da Pedagoga S. M.).

A educação e a socio educação estão intrinsecamente ligadas. A segunda não se faz sem a primeira. Daí a importância da garantia do direito à escolarização. O senso comum afirma que não tem jeito para o adolescente em conflito com a lei. Essa é uma visão punitiva de quem não conhece o poder de transformação da educação (Depoimento da Pedagoga L. M.).

Os depoimentos, acima, apresentam o conjunto de atividades desenvolvidas pelas pedagogas participantes da pesquisa. Analisando as respostas, nota-se a correspondência das mesmas com relação ao que estabelece o inciso $V$ do artigo $5^{\circ}$ da Resolução $n^{\circ} 1 / 2006$ quando trata do perfil do egresso, indicando entre outras atividades a de: "trabalhar, em espaços escolares e não-escolares, na promoção da aprendizagem de sujeitos em diferentes fases do desenvolvimento humano, em diversos níveis e modalidades do processo educativo".

Nascimento e Cunha (2017, p. 76), em pesquisa realizada junto aos estudantes ingressantes nos Cursos de Pedagogia do município de Campos dos Goytacazes, RJ, identificaram que os Projetos Pedagógicos dos Cursos oferecido pelas Instituições de Ensino Superior do município, contemplam o que estabelece a legislação vigente, bem como afirmam que

A diversificação na formação do pedagogo é também um ponto de destaque no parecer e resolução, se forem consideradas as diferentes demandas sociais, assim como para a articulação formação e aspectos inovadores que se apresentam na sociedade contemporânea. A legislação prevê que essa diversificação de saberes pode advir por meio do aprofundamento de conteúdos da formação básica, bem como pela oferta de conteúdos voltados às áreas de atuação profissional.

Ainda sobre a questão levantada junto às respondentes, Libâneo (2001, p. 158) afirma que:

Não há sociedade sem práticas educativas. Pedagogia diz respeito a uma reflexão sistemática sobre o fenômeno educativo, sobre as práticas educativas, para poder ser uma instância orientadora do trabalho educativo. Ou seja, ela não se refere apenas às práticas escolares, mas a um imenso conjunto de outras práticas.

Persp. Online: hum \& sociais aplicada., Campos dos Goytacazes, 27 (10) 63-83-2020 
Sendo assim, o campo de atuação do profissional apresenta-se bastante abrangente, "uma vez que a educação ocorre em muitos lugares e sob variadas modalidades", escolares e não escolares - empresarial, hospital, social, entre outras (LIBÂNEO, 2001, p. 158).

\subsection{Desafios/Dificuldades Vivenciadas}

Perguntados sobre os desafios e dificuldades que perpassam o dia a dia dos Pedagogos entrevistados, percebeu-se que existem muitos a serem superados para que o trabalho seja realizado com maior eficácia e fluidez.

"Uma das dificuldades do trabalho desenvolvido e a elaboração e desenvolvimento de atividade que proporcione uma vida mais saudável, ativa, com atividades que proporcione prazer e alegria de estar dentro da família e também de fazer parte da sociedade. No entanto, fazer com que o mesmo se sinta independente e capaz de realizar seus desejos, é um plano que deve ser aplicado na vida real. Há também uma carência de recursos humanos e financeiros. Não se deve tratar o idoso como alguém que sempre está precisando de ajuda. Deve-se potencializá-los para que realizem as suas atividades. Procuro proporcionar o bem-estar biopsicossocial dos idosos, e assim, trabalhar sua autoestima, percepção visual, emoção, lateralidade, limites, concentração, socialização, criatividade, raciocínio lógico, motivação, desenvolvimento motor, linguagem oral e autonomia dentre de suas possibilidades" (Depoimento da Pedagoga E. J.).

"Questão sensorial da criança, que nós pedagogos não temos acesso a capacitação para conseguir desenvolvê-la na criança, é restrito apenas a fisioterapeutas e Terapeutas Ocupacionais, é de suma importância para o desenvolvimento da criança. Outra dificuldade também é a família, que muitas vezes não possuem conhecimentos e os mesmos aparentam ter problemas psicológicos, cognitivos, o que dificulta no desenvolvimento da criança. Meu objetivo nessa prática é melhorar a qualidade de vida da criança, conseguindo se socializar melhor é frequentar lugares cotidianos de uma criança" (Depoimento da Pedagoga F. L.).

"Uma das maiores dificuldades é uma demanda muito grande de crianças, pois muitas vezes não conseguimos comportar todos. Temos também a questão do espaço físico que ainda não é a ideal. Outra dificuldade é se envolver com a contratação de profissionais e também o relacionamento com a família em que muitas vezes, há a falta de conhecimento, sendo observado a existência de alguma patologia por parte dos pais. O objetivo é que a criança que tenha o atraso consiga se desenvolver conseguindo ter uma melhor qualidade de vida" (Depoimento da Pedagoga O. M.).

"Um dos maiores desafios é conseguir contratar alguém com o perfil ideal para aquele determinado cargo. O meu objetivo é ver sempre o lado humano, tentar ajudar as pessoas, ser um refúgio para os profissionais quando necessário" (Depoimento da Pedagoga R. T.).

"O primeiro desafio, foi conquistar a comunidade daqui. A escola de ontem não pode ser a de hoje, deve haver mudanças pois as pessoas são outras. É necessário buscar atividades interessantes para as crianças e adolescentes realizarem na comunidade para que não ocorra o desinteresse e consequentemente, a evasão" (Depoimento da Pedagoga S. M.).

"São muitos desafios! Trabalhamos com adolescentes com histórico de evasão escolar, repetência, baixa escolaridade e desinteresse pelos bancos escolares; Dificuldade de aceitação das escolas no retorno desses adolescentes; Pouca ou nenhuma oferta de vaga em curso profissionalizante no município de Campos; Pouca ou nenhuma oferta de vaga no mercado de trabalho; questões territoriais; dentre outras" (Depoimento da Pedagoga L. M.).

Persp. Online: hum \& sociais aplicada., Campos dos Goytacazes, 27 (10) 63-83-2020 
Sobre a função do Pedagogo nos espaços não escolares, Holanda (2011, p. 7) destaca:

Diante de novos contextos o pedagogo tem uma função especial que é de desempenhar o papel de motivados, articulados, mediador entre diferentes instâncias do sistema organizacional, não esquecendo-se do crescimento pessoal dos funcionários. Assim o pedagogo deve interagir, ouvir e interpretar as necessidades do espaço aonde acontece o trabalho em equipe.

O Pedagogo possui muitas dificuldades e desafios em sua atuação nos espaços não escolares, sendo um dos seus grandes desafios a formação do indivíduo socialmente, bem como sua interação e participação na sociedade.

Segundo Ribeiro (2003 apud HOLANDA, 2011, p. 7), o pedagogo encontra-se diante de um desafio que é a qualidade social dentro do meio corporativo, qualidade essa que é entendida como "busca da interação do indivíduo consigo mesmo, a visão do todo, a percepção da vida, do ser humano com todas as suas complexidades e sua colocação dentro da sociedade".

\subsection{Autoavaliação profissional}

Nesse ponto da pesquisa, buscou-se provocar o pedagogo à realização de uma autoavaliação profissional.

"Me considero boa, dentro das minhas limitações, sempre tentando buscar mais conhecimentos. Às vezes, me sinto frustrada por não conseguir o resultado esperado com todos. É uma área de muitos desafios" (Depoimento da Pedagoga F. L).

"Percebo a minha atuação com muitos limites, obstáculos. Muito do que é desenvolvido, realizado no sentido de buscar uma vida mais ativa do idoso, se esbarra na falta de recursos da instituição .A pedagoga no resgate do idoso, mostrando novos caminhos, dando outro significado às suas vidas, com novas descobertas, conquistas de novos espaços sociais, dando apoio e desenvolvendo ações que proporcione o bem-estar e uma melhor qualidade de vida. As atividades educativas estimulam a capacidade cognitiva, motora e relações sociais, exercitam a habilidade intelectual tornando esse idoso mais ativo, despertando e estimulando suas capacidades, suas aptidões esquecidas a fim de torná-los sujeitos competentes para entender a velhice, fazendo com que eles sejam reconhecidos como cidadãos que possuem direitos e deveres" (Depoimento da Pedagoga E. J.).

"Procuro trabalhar com muito afeto e responsabilidade. Procuro fazer o melhor para o desenvolvimento da criança para que a mesma tenha uma atuação na sociedade e que possa ser feliz. Não sou perfeita, mas procuro sempre aprender mais" (Depoimento da Pedagoga O.M.).

"Me avalio muito bem, pois sempre trabalhei de forma responsável, dando o melhor de mim. Sou totalmente disponível e sempre tratei a todos da melhor maneira os chamando pelo nome. Quando não sei a resposta para algum questionamento, não ignoro, pelo contrário, busco entender e aprender para atender a necessidade do funcionário" (Depoimento da Pedagoga R. T.).

"Além de ensinar, eu aprendo todos os dias. Todo dia eu tenho uma lição pra vida. Considero minha atuação um sucesso. Adoro o que eu faço aqui. Mistura a minha parte pedagógica com a minha visão social" (Depoimento da Pedagoga S.M.).

"Excelente! Tenho plena convicção da entrega que o meu trabalho exige e o faço com verdadeira dedicação" (Depoimento da Pedagoga L. M.).

Peter Senge et al. (2005) ressaltam a importância de se cultivar as aspirações individuais e a consciência da realidade no cotidiano profissional. Segundo os autores, nas

Persp. Online: hum \& sociais aplicada., Campos dos Goytacazes, 27 (10) 63-83-2020 
últimas décadas, os profissionais foram desafiados a agir com autonomia, tomar decisões, liderar, questionar problemas de forma segura, arriscar-se, mesmo que levem ao fracasso. Acreditam que essas são as competências profissionais fundamentais para todos os profissionais de qualquer área de formação e atuação. Para tanto, afirmam que necessário se faz a construção de um processo de aprendizagem que envolve cinco disciplinas: domínio pessoal, visão compartilhada, modelos mentais, aprendizagem em equipe e pensamento sistêmico.

A prática do domínio pessoal implica uma questão individual, que ocorre por meio de uma reflexão individual. Para Senge et al. (2005, p. 17), “o domínio pessoal é a prática de articular uma imagem coerente de sua visão pessoal - os resultados que você mais deseja criar em sua vida - com uma avaliação realista de sua realidade atual. (...)".

Com relação à disciplina modelos mentais, Senge et al. (2005, p. 17) afirmam que essa envolve a: "capacidades de reflexão e investigação concentra-se no desenvolvimento da consciência de atitudes e percepções - suas e de outros ao seu redor. Trabalhar com modelos mentais também pode ajudar você a definir a realidade atual de forma mais clara e honesta".

\subsection{Quanto à motivação para o trabalho}

Dando continuidade à pesquisa, buscou-se perceber o nível de motivação das profissionais. Os depoimentos, a seguir, revelam:

\footnotetext{
"Quando vemos uma criança evoluindo é muito gratificante, por mais que eu ache que falta recursos e material" (Depoimento da Pedagoga F. L.).

"Me sinto motivada, pois a partir do desenvolvimento das atividades, observa-se uma melhora no nível de participação dos idosos. As oficinas estão sendo aplicadas com a perspectiva de empoderamento dos mesmos, de valorizar o saber e de suas experiências no combate ao isolamento social.” (Depoimento da Pedagoga E. J.).

"Me sinto muito motivada. Adoro esse trabalho e mesmo atuando em outras áreas, esse é o que eu mais gosto de fazer. Tem a possibilidade de transformar vidas" (Depoimento da Pedagoga O. M.).

"Costumo dizer que a motivação vem dentro de você, independente de qualquer situação" (Depoimento da Pedagoga R. T.).

"O Auxiliadora sempre me motiva, me oferecendo vários cursos de capacitação e a comunidade daqui me adotou. Já me sinto parte dela" (Depoimento da Pedagoga S. M).

"Muitíssimo motivada! Atuo com os "invisíveis" da sociedade. Aqueles que atrás de muros, grades e concertinas, ficam longe dos olhos do mundo. Meu dever é fazê-los serem vistos pela prática de atos corretos, mostrando o potencial que possuem. Sigo acreditando que é possível” (Depoimento da Pedagoga L. M).
}

Os depoimentos acima demonstram o quão as pedagogas entrevistadas estão motivadas para continuar exercendo sua função no local em que trabalham. O profissional da pedagogia que atua na presente sociedade possui a necessidade de se manter em busca de novos desafios, motivado a fim de acompanhar as mudanças sociais. Nesse contexto, Pimenta (2005 apud HOLANDA 2011, p. 5) afirma que:

Entende que a educação não só retrata e produz a sociedade, mas projeta a sociedade desejada, vinculando profundamente a educação como prática pedagógica no desafio

Persp. Online: hum \& sociais aplicada., Campos dos Goytacazes, 27 (10) 63-83-2020 
de responder às demandas que o contexto lhe coloca, bem como o possibilitar inúmeras transformações.

Apesar de ainda trazer muitos desafios, percebe-se que atuar como pedagogo não escolar, no que concerne à questão de se estar ou não motivado a desempenhar o trabalho, tem total influência para o resultado final ocorra ou não de forma satisfatória. A motivação é elementar não somente quando o indivíduo já está em efetiva atuação, mas também desde a sua formação, para que isso surta efeito nos seus posteriores objetivos e reflita em suas ações.

\section{CONSIDERAÇÕES FINAIS}

A pesquisa apresentou embasamentos teóricos que perpassam por toda a pedagogia não escolar. Como aporte teórico, utilizou-se dos seguintes autores: Holanda, Libâneo, Severo, dentre outros. Pôde-se observar, enquanto uma dificuldade de pesquisa, a carência de autores, publicações, que abordem de forma direta todas as questões pesquisadas. Vale destacar que se fala de maneira geral sobre o tema, demonstrando que ainda é um campo bastante desconhecido para muitos, uma vez que a pedagogia possui um forte cunho escolar. A revisão de literatura, aliada à pesquisa de campo, possibilitou a percepção de que pedagogo é capacitado para atuar, além da escolar, em diversas áreas e que a pedagogia se apresenta como um campo de atuação bastante amplo e de muitas possibilidades.

A amostra desse estudo envolveu 06 (seis) pedagogas que atuam em espaços não escolares. Ao serem perguntadas sobre a relação do trabalho que desenvolvem com a educação, notou-se uma total ligação entre ambas conforme, por exemplo, o depoimento da pedagoga L. M. que relata: "A educação e a sócio educação estão intrinsecamente ligadas. A segunda não se faz sem a primeira. Daí a importância da garantia do direito à escolarização". A pesquisa de campo aponta, portanto, ser a educação substancial para que o trabalho seja desenvolvido de forma relevante.

Analisando o trabalho desenvolvido pelas pedagogas em seus respectivos campos de atuação, constatou-se que muitos são os desafios e possibilidades enfrentados pelas mesmas, a começar pela sua formação, uma vez que algumas das entrevistadas, quando terminaram a graduação, não se sentiam devidamente aptas a atuar no desempenho de suas funções, necessitando que posteriormente buscassem uma capacitação referente à sua área específica.

Partindo da ideia de que a formação acadêmica influi fortemente na prática profissional, torna-se imprescindível o reconhecimento de que a partir da Resolução $n^{0} 1 / 2006$ o Curso de Pedagogia não está restrito à esfera escolar, ou seja, deve-se ter em mente a formação de profissionais em sua totalidade. Além disso, o pedagogo não deve ficar limitado somente à sua primeira formação, mas sim, buscar sempre a ampliação de conhecimentos por meio da formação continuada, aperfeiçoando-se para que o trabalho desenvolvido seja eficiente e duradouro e, principalmente, enriquecido com a sua prática.

Essa pesquisa buscou mostrar como um pedagogo busca realizar seu trabalho, de acordo com o locus de atuação profissional. Para cada espaço, há método e estratégias diferentes para que o resultado requerido seja alcançado. Vital é o conhecimento detalhado, não somente do seu campo, mas também do público-alvo. É fundamental planejar, mediar e articular as práticas em seu ofício, tendo potencial para resolução de problemas e inovações, possibilitando um trabalho de qualidade. Outro ponto de destaque apresentada pela pesquisa é a necessidade de que cada vez mais o tema objeto de estudo desta pesquisa seja amplamente discutido no interior das instituições de ensino superior, considerando as novas demandas de

Persp. Online: hum \& sociais aplicada., Campos dos Goytacazes, 27 (10) 63-83-2020

seer.perspectivasonline.com.br 
atuação profissional que envolvem a organização de sistemas, unidades, projetos e experiências educacionais no campo educacional e nas áreas emergentes do campo educacional.

\section{REFERÊNCIAS}

ALMEIDA, M. S. de. O pedagogo e sua práxis: desafios e possibilidades na sociedade contemporânea. Universidade Tiradentes - Unit - Tiradentes-MG, 2010. Disponível em: https://pt.slideshare.net/mirianne/o-pedagogo-e-sua-prxis-desafios-e-possibilidades-nasociedade-contempornea. Acesso em: 06 maio 2018.

BRASIL. Conselho Nacional de Educação. Resolução CNE/CP n ${ }^{0}$ 1/2006. Diretrizes Curriculares Nacionais para o Curso de Graduação em Pedagogia, Licenciatura. Disponível em: http://portal.mec.gov.br/cne/arquivos/pdf/rcp01_06.pdf. Acesso em: 16 mar. 2018.

BRASIL. Conselho Nacional de Educação. Parecer CNE/CP No 5/2005. Disponível em: http://portal.mec.gov.br/cne/arquivos/pdf/pcp05_05.pdf. Acesso em: 16 mar. 2018.

BRASIL. Ministério da Educação. Classe hospitalar e atendimento pedagógico domiciliar: estratégias e orientações. Secretaria de Educação Especial. Brasília: MEC/ SEESP, 2002. Disponível em: http://portal.mec.gov.br/seesp/arquivos/pdf/livro9.pdf. Acesso em: 20 jun. 2019.

CARVAlho, F. S.; AZEVEDO, P. G.; CUNHA, T. C. O.; PUGliA, V. M. S. Pedagogia social: relato de uma experiência vivenciada no projeto significarte, tecendo significados por meio da arte. Disponível em: http://www.perspectivasonline.com.br. Acesso em: 22 out. 2018.

CHIAVENATO, I. Gestão de pessoas: o novo papel dos recursos humanos nas organizações. Rio de Janeiro: Campus, 2000.

FELDEN, E. L. et al. O pedagogo no contexto contemporâneo: desafios e responsabilidades. Vivências. v. 9, n.17: p. 68-82, out. 2013. São Paulo. Disponível em: https://docplayer.com.br/342115-O-pedagogo-no-contexto-contemporaneo-desafios-eresponsabilidades-the-educator-in-contemporary-context-challenges-and-responsibilities.html. Acesso em: 22 abr. 2018.

FONSECA, E. S. A situação brasileira do atendimento pedagógico-educacional hospitalar. Educação e Pesquisa, São Paulo, v. 25, n. 1, p. 117-129, jan./jun. 1999. Disponível em: https://www.researchgate.net/publication/26374650_A_situacao_brasileir _ _ do_ atendimento_pedagogico-educacional_hospitalar. Acesso em: 20 jun. 2019.

FREIRE, P. Pedagogia da autonomia: Saberes necessários à prática educativa, 51. ed. Rio de Janeiro: Paz e Terra, 2015.

HOLANDA, T. O papel de pedagogo nas organizações empresariais. 2011. Disponível em: $\quad$ http://www.unifan.edu.br/files/diracademica/TCC\%20Pedagogia\%20Tainara \%20Holanda\%202011\%201.pdf. Acesso em: 22 maio 2018.

Persp. Online: hum \& sociais aplicada., Campos dos Goytacazes, 27 (10) 63-83-2020 seer.perspectivasonline.com.br 
LIBÂNEO, J. C. Ainda as perguntas: o que é pedagogia, quem é o pedagogo, o que deve ser o curso de Pedagogia. In: PIMENTA, Selma Garrido. Pedagogia e pedagogos: caminhos e perspectivas (org.). 3. ed. São Paulo: Cortez, 2011.

LIBÂNEO, J. C; OLIVEIRA, J. F.; TOSCHI, M. S. Educação escolar: políticas, estrutura e organização. 10. ed. São Paulo: Cortez, 2011.

LIBÂNEO, J. C.. Pedagogia e pedagogos: inquietações e buscas. Educ. rev., Curitiba, n. 17, p. 153-176, June 2001. Disponível em: http://www.scielo.br/scielo.php? script $=$ sci_arttext\&pid $=$ S0104-40602001000100012\&lng=en\&nrm=iso. Acesso em: 16 ago 2018.

MATOS, E. L. M.; MUGIATTI, M. T. F. Pedagogia hospitalar: a humanização integrando educação e saúde. Petrópolis, RJ: Vozes, 2006.

MELO, A. L. B. As práticas educativas desenvolvidas por pedagogos em espaços não escolares e os saberes profissionais mobilizados. In: Seminário ANPAE, Goiás, 2012. Disponível em: http://fasam.edu.br/wp-content/uploads/2016/07/AS-PR\%C3\%81TICASEDUCATIVAS-DESENVOLVIDAS-POR-PEDAGOGOS.pdf. Acesso em: 12 jun. 2019.

MICHEL, M. H. Metodologia e pesquisa científica em ciências sociais. 2. ed. São Paulo, Atlas, 2009.

NASCIMENTO, E. O; CUNHA, T. C. O. O perfil dos estudantes ingressantes nos Cursos de Pedagogia das instituições privadas no ensino superior do Município de Campos dos Goytacazes, RJ. Perspectivas Online: Humanas \& Sociais Aplicadas, v. 7, n. 18 (2017). Disponível em: https://ojs3.perspectivasonline.com.br/humanas_sociais_e_aplicadas/ article/view/1012/854. Acesso em: 24 maio 2019.

PIMENTA, S. G. (org.). Pedagogia e pedagogos: caminhos e perspectivas. 3. ed. São Paulo: Cortez, 2011.

LOPES, I. (org.); TRINDADE, A. B.; CADINHA, M. A. Pedagogia empresarial: formas e contextos de atuação. 2. ed. Rio de Janeiro: Wak, 2008.

PASSOS, J. Pedagogia social: contribuição à sua afirmação. Revista Pedagógica Social UFF, v. 2, n. 02, 2017. Disponível em: http://www.revistadepedagogiasocial.uff.br/ index.php /revista/article/download/38/30. Acesso em: 20 maio 2018.

QUIRINO, R. Saberes do pedagogo para a prática educativa nas organizações empresariais. Belo Horizonte: Dissertação (Mestrado) Centro Federal de Educação Tecnológica de Minas Gerais - CEFET-MG, 2005. Disponível em: http://www.et.cefetmg.br/ info/downloads/Raquel\%20Quirino.pdf. Acesso em: 20 jun. 2019.

RIBEIRO, A. E. A. Pedagogia empresarial: atuação do pedagogo na empresa. 5. ed. Rio de Janeiro. WARK, 2008.

SENGE, P. et al. Escolas que aprendem: um guia da quinta disciplina para educadores, pais e todos que se interessam pela educação. Tradução por Ronaldo Cataldo Costa. Porto Alegre: Artmed, 2005. 
SEVERO, J. L. R. L. A formação inicial de pedagogos para a educação em contextos não escolares: apontamentos críticos e alternativas curriculares. In: SILVESTRE, M. A.; PINTO, U. A. (org.). Curso de pedagogia: avanços e limites após as Diretrizes Curriculares Nacionais. São Paulo: Cortez, 2017.

SEVERO, J. L. R. L. et al. Pedagogia e educação não escolar no Brasil: crítica epistemológica, formativa e profissional. 2015. Disponível em: https://repositorio.ufpb.br/ jspui/handle/tede/8217. Acesso em: 16 mar. 2018.

SOARES, R. O Trabalho do Pedagogo Social com Famílias em Situação de Vulnerabilidade Social: elementos para o debate. Revista Pedagogia Social UFF, [S.1.], v. 7, n. 2, maio 2019. Disponível em: http://www.revistadepedagogiasocial.uff.br/index.php/revista/article/view/ 180. Acesso em: 20 jun. 2019.

TORRES, M. O. F.; CLARO, J. A. C. S. Pedagogia empresarial: a atuação dos profissionais da educação na gestão de pessoas. Revista Contrapontos, Itajaí, SC., v. 12, n. 2, p. 207-216, jun. $2012 . \quad$ Disponível em: https://siaiap32.univali.br/seer/index.php/rc/article/view/2214/2245. Acesso em: 20 jun. 2019.

TREVISAN, N. V.; LAMEIRA, L. J. C. R. Formação do educador para pedagogia nas empresas. Revista Educação Especial, Santa Maria, p. 63-69, mar. 2012. Disponível em: https://periodicos.ufsm.br/educacaoespecial/article/view/5033/3050. Acesso em: 20 jun. 2019. 